\title{
The Declaration of the Establishment of the International Society for Formal Ontology
}

On the occasion of the international conference "Quo Vadis, Metaphysics? Dedicated to Peter van Inwagen to commemorate his 75th birthday", which took place in Warsaw from 26 to 29 September 2017, 41 philosophers representing 17 countries have decided to establish the International Society for Formal Ontology (ISFO) based in Poland.

$$
\star \star \star
$$

The date of the establishment of ISFO is September 27, 2017.

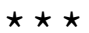

The aims of the ISFO are:

- integration of areas of research dealing with formal ontology,

- support of research in formal ontology,

- promotion of applications of formal ontology,

- connections of formal ontology with related fields.

Members of the founding committee of the ISFO will draft its statute and register the Society in accordance with the applicable Polish legislation.

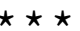

Peter van Inwagen was invited by the founding committee to be the honorary president of the ISFO.

On behalf of the founding members, the declaration is signed by:

\section{Gila Sher}

(University of California, San Diego, USA;

Former Editor in Chief of the Journal Synthese, Netherlands;

Editor of The Journal of Philosophy) 
XIV — Declaration of the Establishment of the International Society for Formal Ontology

\section{Hannes Leitgeb}

(Chair and Head of the Munich Center for Mathematical Philosophy),

\section{Miroslaw Szatkowski}

(Warsaw University of Technology, Poland)

Attachment: List of the founding members of the International Society for Formal Ontology.

Warsaw, September 27, 2017. 


\section{The Founding Members of the International Society for Formal Ontology}

1. Neil Barton (University of Vienna, Austria),

2. Christoph Benzmüller (Free University of Berlin, Germany),

3. Tomasz Bigaj (University of Warsaw, Poland),

4. Andrea C. Bottani (University of Bergamo, Italy),

5. Cezary Cieśliński (University of Warsaw, Poland),

6. Daniel Cohnitz (University of Utrecht, Netherlands),

7. Fabrice Correia (University of Neuchatel, Switzerland),

8. Mario De Caro (Roma Tre University, Italy),

9. Kit Fine (New York University, USA),

10. Peter Forrest (University of New England, Australia),

11. Paweł Garbacz (The John Paul II Catholic University of Lublin, Poland),

12. Michał Głowala (University of Wrocław, Poland),

13. Leon Horsten (University of Bristol, UK),

14. Guido Imaguire (Federal University of Rio de Janeiro, Brazil),

15. William Jaworski (Fordham University, USA,)

16. Janusz Kaczmarek (University of Łódź, Poland,)

17. Christian Kanzian (University of Innsbruck, Austria),

18. Srećko Kovač (University of Zagreb, Croatia),

19. Hannes Leitgeb (University of Munich, Germany),

20. Øystein Linnebo (University of Oslo, Norway),

21. Anna-Sofia Maurin (University of Gothenburg, Sweden),

22. Uwe Meixner (University of Augsburg, Germany),

23. Christopher Menzel (Texas A\&M University, USA),

24. Friederike Moltmann (French National Centre for Scientific Research, France; New York University, USA),

25. Kevin Mulligan (University of Geneva, Switzerland),

26. Thomas Müller (University of Konstanz, Germany),

27. Peter Øhrstrom (Aalborg University, Denmark),

28. Francesco Orilia (University of Macerata, Italy),

29. Tomasz Placek (Jagiellonian University, Poland),

30. Carl Posy (The Hebrew University of Jerusalem, Israel),

31. Graham Priest (University of Melbourne, Australia),

32. Jonathan Schaffer (Rutgers University, New Brunswick, USA),

33. Benjamin Schnieder (University of Hamburg, Germany),

34. Gila Sher (University of California, San Diego, USA),

35. Ted Sider (Rutgers University, New Brunswick, USA), 
36. Peter Simons (University of Dublin, Ireland),

37. Mirosław Szatkowski (Warsaw University of Technology, Poland),

38. Kazimierz Trzęsicki (University of Białystok, Poland),

39. Achille Varzi (Columbia University, USA),

40. Takashi Yagisawa (California State University, Northridge, USA),

41. Dean Zimmerman (Rutgers University, New Brunswick, USA). 